\title{
Technological possibilities of plasma hardening
}

\author{
Mikhail Korotkikh ${ }^{1, *}$, Ludmila Ushomirskaya ${ }^{1}$, Vyacheslav Shestakov ${ }^{1}$, and Dmitriy \\ Ivanov $^{1}$ \\ ${ }^{1}$ Peter the Great St. Petersburg Polytechnic University, 29 Polytechnicheskaya street, Saint- \\ Petersburg, 195251, Russian Federation
}

\begin{abstract}
The article shows the advantages of plasma hardening in comparison with other methods of surface hardening of steel products. Appropriate schemes of hardening of various products are considered and experimental data characterizing the possibility of obtaining a hardened layer of various thickness during the realization of various methods of plasma heating are presented.
\end{abstract}

\section{Introduction}

At the present time a surface heat treatment especially a hardening has widespread applications [1-4]. Various methods for rapid intense heating of surface layers of metal are applied for that purpose. The most widely used methods are: a heating by high-frequency currents [5-14], a laser heating [15-19] and a gas-flame heating [20-21], a plasma heating [22-23] is used for very limited applications.

Limitation of using of the plasma heating is associated with the features of the application of plasma treatment. Most plasma torches and power sources of plasma arc were created for use in the technological processes of plasma cutting or welding of metal workpieces. This fact determined the ability of a plasma arc to rapidly ensure the melting of the surface layers of the metal due to the high intensity of the thermal source.

However, at the present time, laser sources of heating significantly exceed plasma ones by the concentration of thermal energy. Therefore, a laser cutting increasingly displaces the plasma one in the operations of metal workpiece cutting. Besides the quality of laser cutting significantly exceeds the quality of plasma cutting regarding the following criteria: a surface roughness, an accuracy, a material waste reduction, a limitation of a thermal exposure zone and ecological conditions of the process that is most important. At the same time the field of application of laser heating for thermal surface treatment is expanded. The advantage of that kind of treatment is the possibility of localization of the heating area which allows performing the following operations: to treat very limited areas of the surface, to apply hardened reliefs on the surface of the products, to make hardening of screw-threads etc. In addition, such a method makes it possible to carry out a series of localized thermal treatments whose technological capabilities have not been fully studied, and their field of application is limited by the lack of data on their effect on the design parameters of the product (wear resistance, reliability parameters, etc.).

\footnotetext{
*Corresponding author: kmt46@mail.ru
} 
The disadvantage of laser heating is a low value of an efficiency of converting of electrical energy into thermal one in the heating zone.

Heating by high-frequency currents has become widespread [5-14] but its application is limited by the inability to localize the heat source in confined areas and by the low efficiency of converting of electrical energy into thermal one in the heating zone.

\section{Description and analysis of technological process}

Under above-mentioned conditions the use of plasma sources for heat treatment of materials is of interest. It is known that during plasma cutting of steel there is a formation of a layer of metal on the surface of the cut that heated above the austenization temperature. This layer undergoes hardening transformations during rapid cooling due to the heat removal into the metal of the workpiece. The thickness of this layer depends on the velocity of the plasma jet which correlates with the thickness of the metal being cut. Experiments show that the depth of penetration of the phase transformations temperature (this depth determines the thickness of the quenched layer after cutting) is in the range of $0.8 \ldots 2 \mathrm{~mm}$ when the thickness of the workpiece is from 5 to $30 \mathrm{~mm}$. The hardness of this layer depends on the chemical composition of steel, it is usually equal $58 . . .62 \mathrm{HRC}$ when a carbon content is above $0.5 \%$.

The formation of such a layer prevents further mechanical treatment of the workpiece or its welding and requires either removal of this layer by abrasive methods or additional heat treatment.

However, this phenomenon can be used in a number of cases to improve the operational properties of the product if plasma cutting can be the final technological operation.

Under these conditions the cutting speed and its parameters can be assigned not from the condition of maximum cutting productivity but additionally from the condition of formation of a hardened layer of the required thickness on the surface of the workpiece. That thickness can be obtained within rather wide limits (Fig. 1, a). For example, contour processing of discs of cultivators made of $65 \mathrm{G}$ steel can be effectively carried out by plasma cutting, and a surface layer with high hardness is automatically created on the working surface of the disk (Fig. 2, a).

In this case, the plasma torch 1 moves with the programmable speed V1 and the workpiece rotates with a speed V2 that allows cutting out the specified contour. Herewith a hardened layer with a hardness up to HRC62 having an important operational value is formed throughout the workpiece contour.

a)

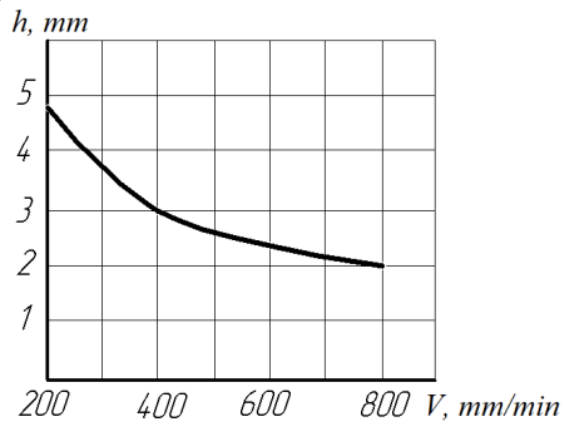

b)

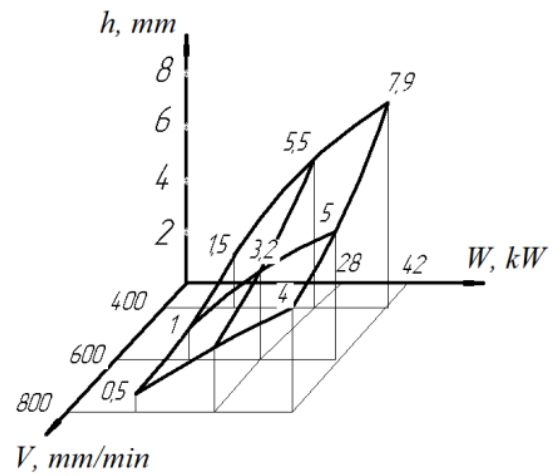

Fig. 1. Average depth of hardened layer formed by plasma hardening: a - in case of melting (cut) of the workpiece stock by the plasma arc (steel 38XН3МФA, I $=320 \mathrm{~A}, \mathrm{U}=180 \mathrm{~B}$, diameter of a nozzle 
of a plasma torch is $4 \mathrm{Mm}$ ); $\mathrm{b}$ - in case of heating by a scanning plasma arc (steel $30 \mathrm{X} 2 \mathrm{~N} 2 \mathrm{M}$, heating spot width is $35 \mathrm{~mm}$ ).

However, surface heat treatment in many cases does not follow with the surface melting of the metal and even completely excludes it. Under these conditions, the use of a plasma arc is substantially limited since at its low speed of movement (with the purpose of heating the metal to the required depth of structural-phase transformations) the surface melting takes place, and at its high speed of movement the depth of heating is very limited.

At the same time, the use of direct-acting plasma torches (the workpiece is an anode) allows to change the intensity of the plasma heating source in wide range and to control the magnitude of the heating spot by applying magnetic deflection systems that move the anode spot along the surface of the workpiece at a high speed and frequency, for example, with the frequency of industrial network $(50 \mathrm{~Hz})$ [24]. Investigation of such a technological heating source has shown that the use of serially produced plasma torches and their power sources, for example, APR-404, allows to obtain a heating spot up to $60 \mathrm{~mm}$ in the direction of scanning plasma arc and the width of the heating zone to $10 \mathrm{~mm}$ in the direction of movement of the plasma torch relative to the workpiece.

In this case the efficiency of conversion of electrical energy into thermal one in the heating zone reaches $50 \%[25,26]$ which is substantially higher than in case of using other heating sources. The experimental data (Fig. 1, b) show that the depth of the hardened zone depends on the speed of movement of such a source over the surface of the workpiece and on the power of the plasma arc. That depth can be adjusted within wide limits from 0.5 to 8 $\mathrm{mm}$ without significant surface melting.

In practice, this makes it possible to implement various schemes of plasma hardening that are simply realized and can be completely automated. For example, the plasma hardening of the working surface of the graders knives (Fig. 2, b) operating under exceptionally hard conditions with intensive abrasive action should ensure an increase in their service life.

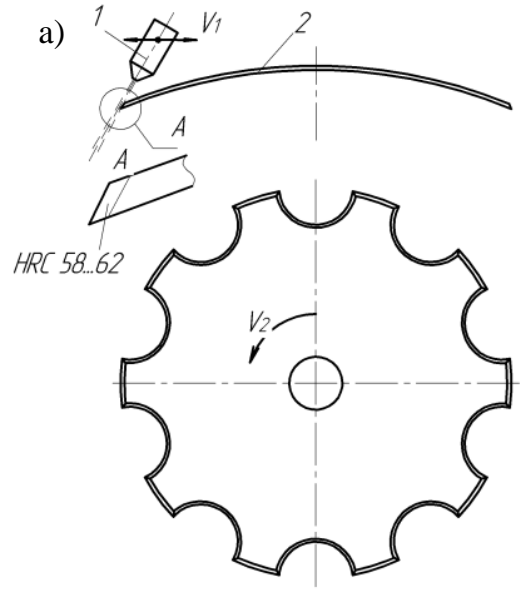

b)

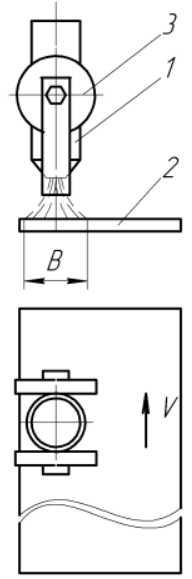

c)

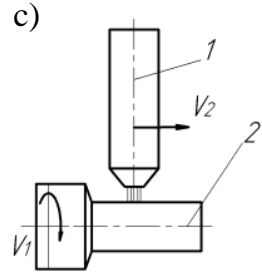

d)

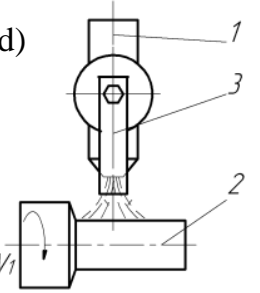

Fig. 2. Examples of technological methods of plasma hardening: a - profile cutting of the cultivator disc with simultaneous hardening of the edge, $b$ - hardening of the edge of the graders knife with a scanning plasma arc, $\mathrm{c}$ - hardening of the neck of the shaft with a plasma arc at a high speed of rotation during the motion of the plasma torch, $\mathrm{d}$-hardening of the neck of the shaft with a scanning plasma arc.

When this process is realized (see Fig. 2, b) the workpiece 2 moves forward under the plasma torch 2 with a magnetic deflection system 3 mounted on it that allow to expand the heating zone B to $40 \ldots 60 \mathrm{~mm}$. 
Calculations show that with sufficient accuracy for practice it is possible to schematize such a heating source as a strip fast-moving source, which allows to carry out calculations both in analytical form, for example according to [27], and by numerical methods (FEM).

When hardening necks of shafts, it is possible to implement a processing scheme in which the anode spot of the plasma arc is located directly on the surface of the shaft (Fig. 2, c). However, in order to prevent surface melting it is required to apply a high speed of the workpiece motion, at which the depth of the hardened layer is small enough. At the same time, repeated action of the arc onto the surface of the workpieces with small diameters $(<100$ $\mathrm{mm}$ ) leads to their overheating, low rate of structural transformations, which prevents the formation of a martensitic layer on the surface. Therefore, in this case there is also rational the application of heating by a scanning plasma arc (Fig. 2, d) which can move along the surface at a much slower speed without surface melting, and the hardened layer can reach a much larger thickness.

In this case the hardening of the neck of the shaft can be performed during one turn of the workpiece.

\section{Conclusions}

Investigations that were carried out allow to formulate the following conclusions:

1. Modern plasma equipment designed for cutting and welding allows to perform the surface thermal treatment of steel workpieces with a wide adjustment of the technological parameters of heat treatment.

2. Plasma hardening can significantly reduce energy costs compared to other methods of heating the material.

\section{References}

1. F. Delaunois, F. Roudet, V. Vitry, Metall. Res. Technol., 115, 401 (2018)

2. F. Czerwinski, ed. Heat Treatment - Conventional and Novel Applications (2012)

3. V. Rudnev, D. Loveless, R. Cook, M. Black, Heat Treatment of Metals, 4, 97-103 (2003)

4. M.M. Radkevich, A.I. Novikov, D.Yu. Fomin, St. Petersburg State Polytechnical University Journal, 4(110), 192-196 (2010)

5. J. Grum, V. Rudnev, Int. J. Mater. Prod. Tec., 29, 1-8 (2007)

6. D. Rodman, C. Krause, F. Nurnberger, F.W. Bach, K. Haskamp, M. Kastner, E. Reithmeier, Steel. Res. Int., 82, 329-336 (2011)

7. V.N. Ivanov, B.M. Nikitin, V.I. Chervinskiy, Induktsionniy nagrev, 4 (22), 9-14 (2012)

8. V.N. Ivanov, B.M. Nikitin, S.I. Brykov, G.A. Gorushin, V.D. Trebich, G.S. Eilenkrieg, Induktsionnyy nagrev, 1 (23), 4-13 (2013)

9. A. Ayday, M. Durman, Materials and technology, 48 (5), 787-790 (2014)

10. D. Rodman, B. Boiarkin, F. Nurnberger, A. Dalinger, M. Schaper, Steel Res Int, 85, 741755 (2014)

11. D. Rodman, F. Nurnberger, A. Dalinger, M. Schaper, C. Krause, M. Kastner, E. Reithmeier, Steel. Res. Int., 85, 415-425 (2014)

12. V.Ya. Frolov, E.A. Smirnova, B.A. Ushin, Induktsionniy nagrev, 2, 50-52 (2009)

13. V.Ya. Frolov, E.A. Smirnova, B.A. Ushin, St. Petersburg State Polytechnical University Journal, 4(110), 187-192 (2010) 
14. V.Ya. Frolov, E.A. Smirnova, B.A. Ushin, Proc. X International Symposium "Plenki $i$ pokrytiya - 2011", 320-326 (2011)

15. T.R. Jervis, M. Nastasi, A.J. Griffin, Jr., T.G. Zocco, T. N. Taylor, S. R. Foltyn, Surface and Coatings Technology, 89, 158-164 (1997)

16. M. Heitkemper, A. Fischer, Ch. Bohne, A. Pyzalla, Wear, 250, 477-487 (2001)

17. G. Duffet, P. Sallamand, A. B. Vannes, Applied Surface Science, 205, 289-296 (2003)

18. M. Bonek, L.A. Dobrzanski, E. Hajduczek, A. Klimpel, Journal of Materials Processing Technology, 175, 45-54 (2006)

19. M.A. Montealegre, G. Castro, P. Rey, J.L. Arias, P. Vázquez, M. González, Contemporary Materials, I-1, 19-30 (2010)

20. H. W. Grönegress, Flame Hardening (1964)

21. S. Jeyaraj, K. P.Arulshri, K. P. Harshavardhan, P.S.Sivasakthivel, Int. J. Eng. Appl. Sciences, 2 (3), 40-44 (2015)

22. V. A. Korotkov, Chemical and Petroleum Engineering, 48(11-12), 705-708 (2013)

23. V.Ya. Frolov, M.V. Dubov, B.A. Ushin, St. Petersburg State Polytechnical University Journal, 2(78), 125-129 (2009)

24. M.T. Korotkikh, I.I. Oleynikov, M.A. Shaterin, V.V. Yaritsyn, Certificate of authorship USSR, no. 980353 (1982)

25. M.T. Korotkikh, L.A. Ushomirskaya, Metalloobrabotka (Metal treatment) 2(68), 23-27 (2012)

26. M.T. Korotkikh, V.S. Medko, Metalloobrabotka, 4(100), 58-61 (2017)

27. A.N. Reznikov, Teplofizika protsessov mekhanicheskoy obrabotki materialov (Termophysics of precesses of mechanical treatment of materials) (1981) 